\title{
Self-Rated Health, Demographic Factors and Depressive Symptoms Among Malaysian Adults
}

\author{
Nur Syahirah Mohd Shah", Nik Nur Wahidah Nik Hashim², Nadzirah Ahmad Basri ${ }^{3 *}$, Siti Fauziah \\ Toha $^{2}$ \\ ${ }^{1}$ Department of Nutrition Sciences, Kulliyyah of Allied Health Sciences, International Islamic \\ University Malaysia, Pahang, Malaysia. \\ ${ }^{2}$ Department of Mechatronics, Kulliyyah of Engineering, International Islamic University Malaysia, \\ Kuala Lumpur, Malaysia. \\ ${ }^{3}$ Department of Psychiatry, Kulliyyah of Medicine, International Islamic University Malaysia, Pahang, \\ Malaysia.
}

\footnotetext{
ABSTRACT

Introduction: Depression risk has been significantly associated with sociodemographic aspects such as education levels and self-rated health. The aim was to investigate the relationship of sociodemographic characteristics particularly level of education, and self-rated health on depressive symptoms among Malaysian adults.

Methods: This is a cross-sectional study among Malaysians who aged 16 to 52 years old. Respondents were recruited via social media, using convenience sampling. Sociodemographic questions include education levels and self-rated health among other questions. Depressive symptoms were measured using Beck Depression Inventory-II, Malay version. The data were analysed using Chi- Square Test. Two-Way of ANOVA was utilized to determine the association of education levels and self-rated health on depressive symptoms.

Results: Chi-Square indicated that age, level of education, job categories and self-rated health had a significant relationship at $\mathrm{p}<0.05$ with key variables used in this study, presence, and absence of depressive symptoms except for gender, race and marital status. Two-way of ANOVA results revealed a significant interaction between self-rated health, level of education and depressive symptoms $(\mathrm{F}=$ $2.711, \mathrm{df}=5, \mathrm{p}<0.05)$.

Conclusion: Malaysian individuals with low education levels showed depressive symptoms and showed a significant association with low self-rated health, however some of them rated themselves as healthy. Therefore, the government needs to make health literacy a priority for everyone, particularly for those with low levels of education and individuals who perceived themselves as mentally healthy.

Keywords: Depression; Self-rated health; Education levels; Malaysian adults

*Corresponding author

Dr. Nadzirah Ahmad Basri

Department of Psychiatry,

Kulliyyah of Medicine,

International Islamic University Malaysia,

Jalan Sultan Ahmad Shah, 25200 Kuantan,

Pahang, Malaysia.

E-mail: nadzirahbasri@iium.edu.my

\section{Article History:}

Submitted: 24 August 2021

Accepted: 18 November 2021

Published: 31 January 2022

ISSN: 2600-898X
} 


\section{INTRODUCTION}

After cardiovascular disease, mental illness is considered as one of the leading causes of death around the world $(1,2)$. According to World Health Organization (WHO), in a group of four people, one of them will be affected by mental illness at least once in a lifetime (3). While in Malaysia, National Health Morbidity Survey (NHMS) reported that the prevalence of mental health has increased with three times increment from $10.7 \%$ in 1996 to $29.2 \%$ in 2015 and is expected to increase in the future (4). Mental illness has been associated with so many factors. Sociodemographic characteristics namely, gender, age, race, marital status, job categories, level of education, and self-rated health (SRH) are some of the aspects that researchers have been closely studying regarding mental illness, especially depression (5-8). According to a study, mental illness and its underlying variables have serious negative consequences for and individual's physical health, family relationships, society and economic burden (9).

\section{Depression and education}

Depression is one of the common illnesses worldwide, that negatively affects feelings, cognitive and behaviour. It can decrease people's ability to function at work and home (10). Previous study has shown that the number of adult Malaysians who reported to have depressive symptoms can be up to more than $20 \%(11)$.

One of the important factors of mental health is the level of education $(5,12)$. Basically, education is about the array of knowledge, skills, and capacities acquired by a learner through formal and experience learning (13). Basic skills like fundamental knowledge, reasoning ability, emotion self-regulation and interactional abilities are very critical components of health (12). This is consistent with a study that declared education as a fundamental determinant of health (13). Education and health have a very complex relationship. It is either through good education that one is able to foster good health or with good health, people can get a good education $(13,14)$.

The positive correlation between education and health was found in multiple of disciplines such as in sociology, economy, and public health. In sociology, education is referred as the psychosocial resources that act as a protective factor against mental illness (15). This point has been validated by a cross-sectional study that was conducted among Germans that demonstrated that people with low education were lacking psychosocial resources and the likelihood of having depressive symptoms was higher than people with higher education (14). The study highlighted those psychosocial resources such as sense of control, delay gratification, resilience and cultural activities are associated with education level and were found to be negatively related to depression. Another study that supports this notion found that the hazard of first depression was 1.86-fold higher in prostate cancer patients with low education background compared to those with high education after they were diagnosed (16). These studies seem to point out that individuals with better education hence better psychosocial resources including coping skills were less likely to have depression.

Meanwhile, in the public health field, high educated people are more likely to choose a healthy lifestyle because they have better understanding on the importance of having good health (17). Therefore, these group of people were found to be able to make a better decision to lead a good life and healthy lifestyle. The study found that without a good education, there will be more stigma on mental health. A survey of Hispanic women found that the more people are informed about depression, the less likely they were to encounter stigma regarding mental health care and thus the more likely they were to be associated with people with depression (13). The previous study added (13), higher educated people, though, were associated with stronger stigma about the use of antidepressants. Therefore, they may prefer to have treatment like psychotherapy as compared to pharmaceutical therapy.

Based on the perspective of health economics, people who have higher education have higher source of income. Therefore, they have access to better health resources (18). They have greater resources to buy healthy meals, exercise on a regular basis, and pay for health care and transportation (17). People with low education, on the other hand, are linked to job insecurity, 
low income, and a lack of assets, making them more vulnerable during difficult times and perhaps leading to poor mental and physical health (15). All these studies have shown that education plays a big role in the aspect of health and that the level of education is associated with the state of people's physical and mental health $(17,18,20)$.

Studies also found that self-rated health could be associated with the level of education of a person. A study about China citizens showed that education level was significant to self-rated health of a person (20). Similar result showed in a study conducted among female IPV survivors where high level of education correlated with low self-rated health (27).

\section{Self-rated health and depression}

According to World Health Organization (16), healthy people can be defined as people who are physically and mentally healthy. These two components are important and interrelated. Moreover, studies have shown that mental health issues have always been associated with poor physical health (17). The self-rated health $(\mathrm{SRH})$ is a straightforward and reliable instrument for assessing population health and predicting morbidity, mortality, and healthcare utilization $(21,25,26)$.

According to some studies, physical health can be explained in terms of sleep quality, regular exercise, balanced diet, cutting down smoking, alcohol and drug used. According to a study, in comparison to the control group, depressed people have much greater prevalence of smoking, markedly unhealthy dietary intake and physically inactive (27). These poor health behaviours are strongly associated with decreased life expectancy. Additionally, they appeared to be at a higher risk for medical problems such as obesity, diabetes type 2, hypertension, and musculoskeletal disorder $(28,29)$. Sleeping is also one of the important terms that need to be given attention as people who are not satisfied with their sleeping patterns, have less duration of sleep time and reduce sleeping efficiency, are at greater risk to have depression (30).

In addition, self-rated health (SRH) is not just about measuring subjective judgement of physical aspects but also non-physical aspects of health (31). Non-physical aspect or psychological aspect like life satisfaction, as well as demographic variables such as age, education level, job status, and lifestyle, are found to be associated to self-rated health in the literature $(21,31)$.

Depression was discovered to be the most significant variable that influences self-rated health in research of factors that predict selfrated health among Chinese residents (21). Similarly, a prospective 10-year cohort analysis was carried in primary care to examine whether self-rated health predicts long-term depression prognosis. During the five-year follow-up period, the study found that self-reported health was a robust and persistent predictor of major depressive symptoms. However, when comparing depression with Post-Traumatic Stress Disorder or PTSD, a study demonstrated that "PTSD is a more fundamental factor than depression when predicting self-rated health" (27 p.1). However, it was conducted among female intimate partner violence (IPV) survivors where their situations were very different from the control group.

\section{Association of socio-demographic factors with mental illness in Malaysia}

There were studies conducted among Malaysians that investigated the sociodemographic factors that may influence mental illness such as depression and generalized anxiety disorder $(5,32,33)$. Results from these studies showed that some of the sociodemographic factors such as levels of education, gender, age, marital status, and health profiles are associated with depression and generalized anxiety disorder. However, the studies that were conducted were not related to these three variables together, rather they were all separately studied. Although some of the foreign studies have shown that these three variables have a significant interaction with each other $(20,34)$, we need to investigate this interaction among Malaysian adult as we have different culture and sociodemographic characteristics.

The current study aims to investigate the relationship of sociodemographic factors namely, gender, race, marital status, job categories including level of education and selfrated health, with depressive symptoms. The 
main research question that this work attempts to address is whether the level of education and self-rated health have significant association with depressive symptoms among Malaysian adults. In this study, we hypothesized that (1) the sociodemographic factors have significant relationship with depressive symptoms, (2) there is a significant different between each group in self-rated health and depression, (3) the level of education also has a statistically and significantly different between each group on depressive symptoms, (4) there is an interaction between level of education, self-rated health and depressive symptoms.

\section{METHODS}

\section{Participant and Procedure}

A cross-sectional study using convenience sampling was conducted among 16 to 52 years old Malaysians through a survey that was distributed through social media platforms, namely Facebook and Twitter from January 2019 to March 2019. The survey was mainly distributed on the Facebook page and Twitter of a Malaysian man who is known to advocate for mental health. Therefore, respondents who filled in the survey include individuals who reported of having been diagnosed with Major Depressive Disorder (MDD) or showing some symptoms of depression. A total of 317 Malaysians participated in the survey.

\section{Sociodemographic questionnaire}

The sociodemographic information was collected from participants. These include information such as age, gender, race, marital status, level of education, job categories and self-rated health. Level of education was grouped into four categories: secondary school, certificate or diploma, bachelor's degree, master or PhD. The difference between unemployed and homemaker is unemployed is a term for a person who during the reference period has no work, available for work and seeking for work (35). However, homemakers are outside the labour force (36).

\section{Beck Depression Inventory-II}

The Malay version of Beck Depression Inventory-II (BDI-II) was used to measure depressive symptoms among the participants. The original English edition of the BDI-II contains 21 items that evaluate the severity of depression's emotional, cognitive, performance, and psychomotor components.
However, due to the sensitivity of culture and religion in Malaysia, the Item 21(loss of libido) was excluded from the inventory. BDI-Malay is divided into two subscales which are cognitive/ affective subscale which form the first 13 items and the rest are psychomotor/performance subscale. The respondents indicated on a scale from 0 to 3 for the severity of their current state to each symptom. The items are then added together to get a score between 0 and 60 , with higher scores signifying greater depression severity. The reliability coefficient of BDI- II (0.91) was acceptable and strong according to a study conducted by Mukhtar and Oei (37). The respondents who scored below 20 (mild to borderline) were classified as non-depressed. While respondents who score above 21 (moderate to severe) were classified as depressed (37).

\section{Self-rated health}

Participants rated their health by responding to the question, "In general, how do you rate your health?". The responses were grouped in three categories, not healthy, healthy and very healthy. This assessment has been proven and validated to evaluate general health and wellbeing $(5,38)$. This single question of assessment is about measuring subjective judgement of physical aspect of health.

\section{Data Analysis}

This current study used SPSS version 24 for analysis. Descriptive analysis was utilized for sociodemographic data of the participants. Percentage and frequency were used to represent the sociodemographic characteristics like gender, race, marital status, educational levels, job status, and self-rated health. Age of participants was represented by mean and standard deviation (SD). Chi-Square was utilized to find the significance of sociodemographic variables with non-depressed and depressed groups. Two- way of ANOVA was utilized to measure the association of depression, self-rated health, and level of education among participants. In two-way of ANOVA, depression variable was measured in continuous form. While, in Chi-Square test, depression variable was classified as categorical variable. Tukey HSD as post hoc test was conducted to find the mean difference and association between each group in level of education and self-rated health. 


\section{Ethical Clearance}

This research project was granted ethical approval from IIUM Research Ethics Committee (IREC Code: 2019-006). Participants were given a written information about the study. Their participations in this study were totally voluntarily and their responses were treated confidentially.

\section{RESULTS}

Table I presents the socio-demographic characteristics by presence of depressive symptoms status, 129 respondents had depressive symptoms, 188 respondents had no depressive symptoms. The Chi-square indicated the significant of association between the variables and depressive symptoms. The descriptive analysis indicates that $41 \%(n=129)$ of the total respondents scored in the high spectrum on BDI-II and there was no significance in gender. Most respondents $(68.85 \%)$ were aged between 16-28 years old, and they showed no depressive symptoms, and their average age was 28.26 \pm 6.97 . Respondents under the age group of 29-40 years old were found to be more depressed than other age groups $(54.39 \%)$. Malaysia is a multi-ethnic country, but the majority of the respondents who had depressive symptoms were Malay and only 4 respondents were from the group of minorities. This may be due to the fact that majority of the respondents were of Malay race.

The proportion of respondents who completed education in secondary school $(62.5 \%)$ and diploma, or certificate $(57.1 \%)$ with depressive symptoms was higher than the respondents with no depressive symptoms in both groups of levels of education, $37.5 \%$ and $42.9 \%$ accordingly. Among all four of the job categories, homemakers who showed depressive symptoms (69.2) were greater in number than that of homemakers with no depressive symptoms (30.8\%). Meanwhile, half of the respondents who were full-time workers showed no depressive symptoms (58.3\%). Based on self-rated health,most of the depressed people rated themselves as healthy and it was higher than non-depressed people (74.4\% vs $25.6 \%)$.

Significant associations $(\mathrm{p}<0.05)$ were found in age, level of education, job categories and selfrated health between the depressed and non- depressed respondents. However, gender, race and marital status did not show any significance (Table I ).

The two-way of ANOVA was conducted to compare the main effects of self-rated health and level of education as well as their interactions effects on depression. As indicated in Table II, there were significant main effects of education $(F=5.035, p=0.002)$ and self-rated health $(\mathrm{F}=47.647, \mathrm{p}<0.001)$ on depression which indicates a very strong significant correlation. The same can be said for interaction effect of education and self-rated health which shows significant interaction effect of these variables on depression $(\mathrm{F}=2.711, \mathrm{p}=0.020)$ (Table II).

The result in table III indicated a significant difference in depression among each level of education and self-rated health. Pairwise comparisons of the means using Tukey HSD revealed the significant differences between master or PhD and other education levels. More specifically, in the master or $\mathrm{PhD}$ level were significantly lower than secondary schools in the score of depression $(\mathrm{M}=18.02, \mathrm{SD}=2.98$, $\mathrm{p}<0.001)$. In terms of self-rated health, respondents who rated as not healthy had a higher significant than who rated as very healthy in the score of depression $(M=38.56$, $\mathrm{SD}=2.84, \mathrm{p}<0.001)$.

\section{DISCUSSION}

This study's main objectives were to investigate the relationship of education levels and selfrated health with depressive symptoms in Malaysia along with other sociodemographic variables. Based on the analysis results, our first hypothesis in this cross-sectional study is partially accepted, we found that age, level of education, job categories and self-rated health were significantly associated with the key variables of presence of depressive symptoms and absence of depressive symptoms which were similar to previous study $(5,39)$ except race, gender and marital status.

In the current study, the full-time workers reported less depressive symptoms. This association is significant which similar to previous study (40). Previous study revealed that full-time worker had a secure job, a great support from colleague and a good influence as 
Table I: Socio-Demographic Characteristics of Participants with Key Variables used in the Study, categorized according to the presence and absence of depressive symptoms.

\begin{tabular}{|c|c|c|c|c|}
\hline Variables, n (\%) & & $\begin{array}{l}\text { Presence of } \\
\text { depressive } \\
\text { symptoms } \\
(\mathrm{n}=129)\end{array}$ & $\begin{array}{l}\text { Absence of } \\
\text { depressive } \\
\text { symptoms } \\
(\mathrm{n}=188)\end{array}$ & p-value \\
\hline Gender & & & & 1.00 \\
\hline Male & & $22(41.5 \%)$ & $31 \quad(58.5 \%)$ & \\
\hline Female & & $107(40.5 \%)$ & $157(59.5 \%)$ & \\
\hline Age, mean(SD) & $28.26 \pm 6.97$ & & & $<0.001^{*}$ \\
\hline 16 - 28 years old & & $57(31.2 \%)$ & $126(68.8 \%)$ & \\
\hline 29 - 40 years old & & $62(54.4 \%)$ & $52(45.6 \%)$ & \\
\hline $41-52$ years old & & $10(50.0 \%)$ & $10(50.0 \%)$ & \\
\hline Race & & & & 0.052 \\
\hline Malay & & $125(39.9 \%)$ & $188(60.1 \%)$ & \\
\hline Indian & & $1 \quad(100 \%)$ & & \\
\hline Others & & $3 \quad(100 \%)$ & & \\
\hline Marital status & & & & 0.53 \\
\hline Married & & $50(42.4 \%)$ & $68(57.6 \%)$ & \\
\hline Divorced & & $9 \quad(33.3 \%)$ & $18(66.7 \%)$ & \\
\hline Single & & $69(40.4 \%)$ & $102(59.6 \%)$ & \\
\hline Widow & & $1(100 \%)$ & & \\
\hline Level of education & & & & $<0.001^{*}$ \\
\hline Secondary school & & $25(62.5 \%)$ & $15(37.5 \%)$ & \\
\hline Certificate/Diploma & & $48(57.1 \%)$ & $36(42.9 \%)$ & \\
\hline Undergraduate & & $51(30.2 \%)$ & $118(69 . .8 \%)$ & \\
\hline Master/ PhD & & $5 \quad(20.8 \%)$ & $19(79.2 \%)$ & \\
\hline Job Categories & & & & $0.003^{*}$ \\
\hline Full-time worker & & $58(41.7 \%)$ & $81 \quad(58.3 \%)$ & \\
\hline Part-time worker & & $9(52.9 \%)$ & $8 \quad(47.1 \%)$ & \\
\hline Student & & $15(25.4 \%)$ & $44 \quad(74.6 \%)$ & \\
\hline Homemaker & & $18(69.2 \%)$ & $8 \quad(30.8 \%)$ & \\
\hline Unemployed & & $29(38.2 \%)$ & $47 \quad(61.8 \%)$ & \\
\hline Self-Rated Health & & & & $<0.001^{*}$ \\
\hline Not healthy & & $18(94.7 \%)$ & $(5.3 \%)$ & \\
\hline Healthy & & $64(74.4 \%)$ & $22(25.6 \%)$ & \\
\hline Very healthy & & $47(22.2 \%)$ & $165(77.8 \%)$ & \\
\hline
\end{tabular}
${ }^{*} \mathrm{p}<.05$,

compared to part-time worker hence, experienced less depressive symptoms (40). A group of working women have also been identified as less vulnerable to depression as compared to homemakers especially from the rural area and had low socio-economic status (41). An epidemiological study among pregnant women also supported our findings that homemakers had a high proportion of depressive symptoms as compared to working women and students (42). The previous study added (42), possible factors that contributed to this result were low level of education, singleparent family, low income, lack of support and stressful life events. The present study found an interesting result whereby the distribution of unemployed people with depressive symptoms were lower than people with no depressive symptoms. 
Table II :The result of two-way of ANOVA for depression, $\mathbf{n = 3 1 7}$

\begin{tabular}{lccccc}
\hline Variables & Sum of squares & df & $\begin{array}{c}\text { Mean } \\
\text { squares }\end{array}$ & F & p-value \\
\hline Education & 1957.434 & 3 & 652.478 & 5.035 & $0.002^{*}$ \\
Self-rated health & 12348.061 & 2 & 6174.030 & 47.647 & $0.000^{*}$ \\
$\begin{array}{l}\text { Education*Self- } \\
\text { rated health }\end{array}$ & 1756.315 & 5 & 351.263 & 2.711 & $0.020^{*}$ \\
Error & 39650.821 & 306 & 129.578 & & \\
Total & 187592.000 & 317 & & & \\
\hline
\end{tabular}

*significant at the level $\mathrm{p}<0.05$

Depression variable was measured in continuous variable

Table III: The result of pairwise comparisons between each variables

\begin{tabular}{|c|c|c|c|c|}
\hline Level of education & Mean (SD) & Level of education & Mean difference & p-value \\
\hline \multirow[t]{3}{*}{ Secondary school } & $33.1(2.40)$ & $\begin{array}{ll}\text { Certificate } & \text { or } \\
\text { Diploma } & \end{array}$ & 4.31 & 0.140 \\
\hline & & Bachelor's degree & 6.65 & $0.026^{*}$ \\
\hline & & Master or PhD & 15.08 & $0.000^{*}$ \\
\hline \multirow{3}{*}{$\begin{array}{l}\text { Certificate } \\
\text { Diploma }\end{array}$} & $28.79(1.66)$ & Secondary school & -4.31 & 0.140 \\
\hline & & Bachelor's degree & 2.34 & 0.335 \\
\hline & & Master or PhD & 10.77 & $0.002^{*}$ \\
\hline \multirow[t]{3}{*}{ Bachelor's Degree } & $26.45(1.76)$ & Secondary & -6.65 & $0.026^{*}$ \\
\hline & & Certificate or & -2.34 & 0.335 \\
\hline & & Master or $\mathrm{PhD}$ & 8.43 & $0.015^{*}$ \\
\hline \multirow[t]{3}{*}{ Master or $\mathrm{PhD}$} & $18.02(2.98)$ & Secondary school & -15.08 & $0.000^{*}$ \\
\hline & & Certificate or & -10.77 & $0.002^{*}$ \\
\hline & & Bachelor's Degree & -8.43 & $0.015^{*}$ \\
\hline \multicolumn{2}{|l|}{ Self-rated health } & Self-rated health & & \\
\hline \multirow[t]{2}{*}{ Not healthy } & $38.56(2.83)$ & Healthy & 8.67 & $0.008^{*}$ \\
\hline & & Very healthy & 22.09 & $0.000^{*}$ \\
\hline \multirow[t]{2}{*}{ Healthy } & $29.89(1.60)$ & Not healthy & -8.67 & $0.008^{*}$ \\
\hline & & Very healthy & 13.42 & $0.000^{*}$ \\
\hline \multirow[t]{2}{*}{ Very healthy } & 16.47 (1.28) & Not healthy & -22.09 & $0.000^{*}$ \\
\hline & & Healthy & -13.42 & $0.000^{*}$ \\
\hline
\end{tabular}

*Significant value at $\mathrm{p}<.05$ 
This finding contradicts to the previous studies which demonstrated that the prevalence of depression among unemployed was high especially among females due to the lack of job opportunities, sexism, and prejudice (43). Another study found that unemployed older adults were more likely to experience depression than unemployed younger adults (44).

However, there was a longitudinal study which reported that people who were unemployed were found to have no significant effect on health (45). Despite challenging labour market conditions, unemployment did not result in a significant decline in health (45). Nevertheless, the study did not clearly define the measure of health.

This study also shows that gender, marital status and race were not found to be significant. In terms of marital status and gender, this finding contradicts with those of previous studies whereby the number of females and unmarried individuals who reported to have mental health illnesses were more than the males and married individuals $(5,46,47)$. However, the present study indicates that among married people had no significant relationship with depressive symptoms. The same pattern also applies to single individuals in the study.

In terms of the significant difference between different races and severity of depression, our finding shows that the relationship between these variables is insignificant. This finding contradicts to previous study where minority reported to have more depressive symptoms as compared to the majority of race or ethnicity $(48,49)$. For example, the prevalence of probable depression was greater among the nonHispanic Black and Hispanic as compared to non-Hispanic (49). However, due to limited number of ethnicity and racial diversity in our small size of participants, it may affect the generalizability of the results to other minority groups. Hence, we are not able to discuss this further.

Another highlighted finding in our study is the levels of education which have a significant relationship with depressive symptoms which also proved our second hypothesis. This finding aligns with previous studies that revealed that low educated people had higher risk of having depression than the high educated people $(14,50)$ especially among mothers, the mothers with high education were less likely to experience postpartum depression than low educated mothers (51). Level of education could also influence the expression of postpartum depression $(51,52)$. Previous studies have proved that education is fundamental in keeping a healthy mental state. People who have higher education are more prone to choose and live a healthy lifestyle as they are more knowledgeable about health than people who have low education and they can get better access to the best health facility as compared to low-educated people $(12,13,47,53)$. Education levels were also reported to be associated significantly with general health literacy (54). Our findings contradict to a previous study that indicated people with high educational performance could also be as distinctive factor to other mental illness like bipolar disorder (55).

Low self-rated health also has shown to have a significant interaction with the presence of depressive symptoms in the previous studies among young and older adults $(39,56)$ consistent with our study that proved the third hypothesis. This finding supports the previous studies that highlighted that low self-rated health was a strong and consistent predictor of risk for depressive symptoms $(21,57)$. With the presence of chronic diseases and functional disability could also make people prone to negatively perceived their health and experienced symptoms of depression (58).

The term self-rated health and self-perceived health is similar to each other where both need a person to assess his or her own overall health based on own's judgement. When it comes to own perception and judgement, it could be misleading and not describe the actual health of a person accurately. Hence, they could lead to underestimation of health risk. This situation was illustrated in a study among South Koreans (59). According to the study, approximately $50 \%$ of men and $30 \%$ of women who reported their health as good had three or more cardiovascular risk factors. Even among those at high risk for cardiovascular disease, $78 \%$ of men and $54.3 \%$ of women believed they were in good health (42). One of the possible reasons that could explain this surprising result 
of the previous study was lack of knowledge on health among those individuals. When people lack knowledge about their own health, they may perceive their health not accurately, hence adopt and maintain risk behaviours or unhealthy lifestyle. This explanation could explain our finding based on Chi-square analysis where most people with depressive symptoms rated themselves as healthy.

Our study also found that, self-rated health and level of education could go hand in hand in contributing to the state of mental health as based on our ANOVA analysis and Tukey HSD, these two variables had a significant interaction on depressive symptoms where people who have low level of education and low self-rated health are riskier to get depression than high-educated and healthy people. This finding supports the previous study among ederly in South Europe where depressive symptoms had a significant effect on a association of level of education and selfrated health. It was suggested that people who had low education were prone to rate their health poorly and experienced depressive symptoms (60). On a recent study also showed that the increased educational attainment was associated with reductions in depression and anxiety (20). Education is a protective factor against depression and could influence the selfrated health. This could be explained with better education, it could protect against stressful experience such as financial struggle and have better psychosocial resources to cope with it (15-18).

However, some of the previous studies against this notion where they suggested that there was no causal effect between education and depressive symptoms $(61,62)$. Nevertheless, these studies only explained the causal effect between education and depressive symptoms without considering the self-rated health or any physical health condition. The sample size was also smaller than the studies that support our findings.

Self-rated health can be very subjective. Both physical and mental health aspects could be considered by participants when they rated their health. It is either they considered one of these two aspects or both at the same time (31). Therefore, this could be the reason for selfrated health to be one of the factors that contributed to depression because there was a longitudinal study conducted among people who had no prior history of depression showed that poor self-perceived mental health was associated with future depressive symptoms but could be influenced by epigenetic and inflammatory mechanisms (63). Additionally, since our study used the general self-rated health which also described that our samples used their own perception and judgement in rating their overall health, future studies are encouraged to be more specific which physical aspect or mental aspect that want to measure. To pinpoint other limitations of our study, since we conducted a cross-sectional study using convenience sampling and using online platforms advocating for mental health issues, it has its bias effects, which we could not use to generalize to other Malaysian population. In addition to that, this study might also lack of generalization because of our sample was small and thus, non-representative of Malaysian adults.

\section{CONCLUSION}

In conclusion, the present study pointed out that education levels was significantly associated with depressive symptoms of individuals whereby those with lower levels of education background (diploma and below) were more inclined to manifest depressive symptoms than those with higher education levels (bachelor degree and above). This indicates the need to increase awareness about mental health literacy to individuals with lower education levels so that they can seek help as soon as they recognize the symptoms. This study also found a significant proportion of individuals who showed depressive symptoms rated themselves as healthy compared to those who did not show depressive symptoms. This is rather worrisome because if this is the case, it may be the reason that many with depressive symptoms do not seek for help from mental health professionals. Therefore, we need to carry out preventive mental health awareness programs even to individuals who consider themselves healthy and free of stress or depression.

\section{CONFLICT OF INTEREST}

The authors acknowledge that the publishing of this paper does not have any conflict of interest. 


\section{ACKNOWLEDGEMENT}

This study was supported by Fundamental Research Grant Scheme (FRGS/1/2018/TK04/UIAM/02/7) from the Ministry of Education (MOE). The funding is used to pay the graduate research assistance's stipend.

\section{REFERENCES}

1. Ngo CK, Zulkifli CW, Vellasamy RA, Suresh R. ) Depression, Anxiety and Stress among Undergraduate Students: A Cross Sectional Study. Open J Epidemiol [Internet]. 2010 [cited 2020 Jan 2];5:260-8. Available from: http://www.scirp.org/journal/ojepihttp: //dx.doi.org/10.4236/ojepi.2015.54030htt p://dx.doi.org/10.4236/ojepi.2015.54030h ttp://creativecommons.org/licenses/by/ $4.0 /$

2. Rostamzadeh $\mathrm{M}$, Anantharaman RN, Tong DYK. Sense of Place on Expatriate Mental Health in Malaysia. Int J Soc Sci Humanit. 2013;2(5):360-5.

3. WHO. WHO | Mental disorders affect one in four people. WHO. World Health Organization; 2013.

4. National Institute of Health. Malaysian Mental Healthcare Performance. 2017.

5. Cheah YK, Azahadi M, Phang SN, Abd Manaf NH. Sociodemographic, Lifestyle, and Health Factors Associated With Depression and Generalized Anxiety Disorder Among Malaysian Adults. J Prim Care Community Heal. 2020;11.

6. Ishida M, Montagni I, Matsuzaki K, Shimamoto T, Cariou T, Kawamura T, et al. The association between depressive symptoms and self-rated health among university students: a cross-sectional study in France and Japan. BMC Psychiatry [Internet]. 2020;20(1). Available from: https://doi.org/10.1186/s12888-02002948-8

7. Bezerra H de S, Alves RM, Nunes AD d., Barbosa IR. Prevalence and Associated Factors of Common Mental Disorders in Women: A Systematic Review. Public Health Rev. 2021;42.

8. Farooq S, Khan T, Zaheer S, Shafique K. Prevalence of anxiety and depressive symptoms and their association with multimorbidity and demographic factors: a community-based, cross-sectional survey in Karachi, Pakistan. BMJ Open [Internet]. 2019 Nov 1 [cited 2021 Feb 5];9(11):29315. Available from: http:/ / bmjopen.bmj.com/

9. Cheng $\mathrm{Y}, \mathrm{Li} \mathrm{X}$, Lou $\mathrm{C}$, Sonenstein $\mathrm{FL}$, Kalamar A, Jejeebhoy S, et al. The association between social support and mental health among vulnerable adolescents in five cities: Findings from the study of the well-being of adolescents in vulnerable environments. J Adolesc Heal. 2014 Dec 1;55(6):S31-8.

10. Torres F. What is Depression? [Internet]. American Psychiatric Association. 2020. Available from: https://www.psychiatry.org/patientsfamilies/depression/what-is-depression

11. Abd Rahman R, Badilla Idris I, Ibrahim $H$, Yaacob Latif J, Tun Razak B, Lumpur K, et al. Risk Factors of Depression, Anxiety and Stress Among Adults Attending Primary Health Clinics in an Urban Area in Klang Valley, Malaysia. Malaysian J Med Heal Sci. 2020;16(1):2636-9346.

12. Gil-Lacruz M, Gil-Lacruz AI, Gracia-Pérez ML. Health-related quality of life in young people: The importance of education. Health Qual Life Outcomes [Internet]. 2020 [cited 2020 Oct 17];18(1). Available from: https://doi.org/10.1186/s12955-02001446-5

13. Hahn RA, Truman BI. Education improves public health and promotes health equity. Int J Heal Serv [Internet]. 2015 Oct 1 [cited 2020 Oct 27];45(4):657-78. Available from: /pmc/articles/PMC4691207/?report=abst ract

14. Niemeyer $H$, Bieda A, Michalak J, Schneider S, Margraf J. Education and mental health: Do psychosocial resources matter? SSM - Popul Heal. 2019 Apr 1;7:100392.

15. Ross CE, Chia-Ling Wu. The links between education and health. Am Sociol Rev. 1995;60(5):719-45.

16. Friberg AS, Rask Moustsen I, Benzon Larsen S, Hartung T, Wreford Andersen E, Halgren Olsen $\mathrm{M}$, et al. Educational level and the risk of depression after prostate cancer. Acta Oncol (Madr). 2019 May 4;58(5):722-9.

17. Ge T, Zhang Q, Lu J, Chen G, Sun M, Li X. Association between education and health outcomes among adults with disabilities: Evidence from Shanghai, China. PeerJ. 
2019;2019(2).

18. Albert C, Davia MA. Education is a key determinant of health in Europe: A comparative analysis of 11 countries. Health Promot Int [Internet]. 2011 Jun [cited 2020 Dec 2];26(2):163-70. Available from:

https://pubmed.ncbi.nlm.nih.gov/209350 91/

19. Rodríguez López S, Colantonio SE, And †, Celton DE. Socioeconomic Inequalities in Self-reported Health and Physical Functioning in Argentina: Findings from The National Survey on Quality of Life of Older Adults 2012 (ENCaVAM). J Biosoc Sci. 2017;49:597-610.

20. Jones DP, Wootton RE, Gill D, Carter AR, Gunnell D, Munafò MR, et al. Mental Health as a Mediator of the Association Between Educational Inequality and Cardiovascular Disease: A Mendelian Randomization Study. Vol. 10, Journal of the American Heart Association. 2021.

21. Cai J, Coyte PC, Zhao H. Determinants of and socio-economic disparities in self-rated health in China. Int J Equity Health. 2017;

22. Dekel R, Shaked O, Ben-Porat A, Itzhaky H. The Interrelations of Physical and Mental Health: Self-Rated Health, Depression, and PTSD Among Female IPV Survivors. Violence Against Women. 2020;26(34):379-94.

23. WHO. Promoting Mental Health. 2004.

24. Gebre A, Taylor RD. Association of Poor Kin Relations, College Adjustment and Psychological Well-Being among African American Undergraduates. J Child Fam Stud. 2017;26:217-24.

25. Arroyo E, Renart G, Saez M. How the economic recession has changed the likelihood of reporting poor self-rated health in Spain. Int J Equity Health [Internet]. 2015 Dec 18 [cited 2020 Dec 2];14(1):149. Available from: http://www.equityhealthj.com/content/1 $4 / 1 / 149$

26. Depa J, Hilzendegen C, Tinnemann P, Stroebele-Benschop N. An explorative cross-sectional study examining selfreported health and nutritional status of disadvantaged people using food banks in Germany. Int J Equity Health [Internet]. 2015 Nov 24 [cited 2020 Dec 2];14(1). Available from: /pmc/articles/PMC4658762/?report=abst ract

27. Jia H, Zack MM, Gottesman II, Thompson WW. Associations of Smoking, Physical Inactivity, Heavy Drinking, and Obesity with Quality-Adjusted Life Expectancy among US Adults with Depression. Value Heal. 2018 Mar 1;21(3):364-71.

28. Jahrami H, Saif $Z$, AlHaddad M, Faris MAI, Hammad L, Ali B. Assessing dietary and lifestyle risk behaviours and their associations with disease comorbidities among patients with depression: A casecontrol study from Bahrain. Heliyon. 2020 Jun $1 ; 6(6)$.

29. Cakmak S, Gen E. Relationship between quality of life, depression and anxiety in type 1 and type 2 diabetes. Dusunen Adam. 2020;33(2):155-69.

30. Furihata R, Saitoh K, Suzuki M, Jike M, Kaneita Y, Ohida T, et al. A composite measure of sleep health is associated with symptoms of depression among Japanese female hospital nurses. Compr Psychiatry. 2020 Feb 1;97.

31. Schüz B, Wurm S, Schöllgen I, TeschRömer C. What do people include when they self-rate their health? Differential associations according to health status in community-dwelling older adults. Qual Life Res. 2011;20(10):1573-80.

32. Cheah YK, Azahadi M, Phang SN, Abd Manaf NH. Sociodemographic, lifestyle and health factors associated with depression among adults in malaysia: An ethnic comparison. J Heal Transl Med. 2019;22(1):33-40.

33. Kader Maideen SF, Mohd Sidik S, Rampal L, Mukhtar F. Prevalence, associated factors and predictors of depression among adults in the community of Selangor, Malaysia. PLoS One. 2014 Apr 22;9(4).

34. Chlapecka A, Kangstrom A, Cermakova P. Educational attainment inequalities in depressive symptoms in more than 100,000 individuals in Europe. Eur Psychiatry. 2020;1(63):1-7.

35. Hussmanns R. Measurement of employment,unemployment and underemployment- Current international standards and issues in their application. [Internet]. Bulletion of Labour Statistics. 1989 [cited 2021 Oct 15]. p. 1. Available from:

https://www.ilo.org/public/english/bur eau/stat/download/articles/2007-1.pdf 
36. Davis B. What refers to the percentage of the labor force that is wiling and able to work does not currently have a job and is actively looking for work? [Internet]. MVOrganizing. 2020 [cited 2021 Oct 15]. Available from:

https://www.mvorganizing.org/whatrefers-to-the-percentage-of-the-laborforce-that-is-willing-and-able-to-workdoes-not-currently-have-a-job-and-isactively-looking-forwork/\#Is_a_homemaker_considered_une mployed

37. Mukhtar F, Oei TPS. A review on assessment and treatment for depression in malaysia [Internet]. Vol. 2011, Depression Research and Treatment. Hindawi Limited; 2011 [cited 2020 Dec 2]. Available from: /pmc/articles/PMC3143455/?report=abst ract

38. Chan YY, Teh $\mathrm{CH}$, Lim KK, Lim KH, Yeo PS, Kee CC, et al. Lifestyle, chronic diseases and self-rated health among Malaysian adults: results from the 2011 National Health and Morbidity Survey (NHMS). BMC Public Health. 2015 Aug 6;15(1).

39. Millán-Calenti JC, Sánchez A, Lorenzo T, Maseda A. Depressive symptoms and other factors associated with poor selfrated health in the elderly: Gender differences. Geriatr Gerontol Int. 2012;12:198-206.

40. Nielsen HB, Gregersen LS, Bach ES, Dyreborg J, Ilsøe A, Larsen TP, et al. A comparison of work environment, job insecurity, and health between marginal part-time workers and full-time workers in Denmark using pooled register data. Vol. 63, Journal of occupational health. 2021. p. e12251.

41. Mohammadi A, Aghdam GA, Ranji S. Comparison of postpartum depression of working women and housewives and its relationship with social support and marital adjustment. In: Procedia - Social and Behavioral Sciences. Elsevier; 2011. p. 1837-9.

42. Fall A, Goulet L, Vézina M. Comparative study of major depressive symptoms among pregnant women by employment status. Springerplus [Internet]. 2013 Dec 30 [cited 2021 Feb 7];2(1):1-11. Available from: https://springerplus.springeropen.com/a rticles/10.1186/2193-1801-2-201

43. Mamun MA, Akter S, Hossain I, Faisal
MTH, Rahman MA, Arefin A, et al. Financial threat, hardship and distress predict depression, anxiety and stress among the unemployed youths: A Bangladeshi multi-city study. J Affect Disord. 2020;276(July):1149-58.

44. Woo K, Zhang Z. The Effect of Unemployment in Depression by Age Group: Using 12 States' Data from the Behavioral Risk Factor Surveillance System. J Korean Acad Community Heal Nurs [Internet]. 2020 Dec 1 [cited 2021 Feb 7];31(4):436. Available from: https://jkachn.org/DOIx.php?id=10.1279 9/jkachn.2020.31.4.436

45. Ronchetti J, Terriau A. Impact of unemployment on self-perceived health: Evidence from French panel data. Eur J Heal Econ [Internet]. 2019 [cited 2021 Jan 4];20(6):879-89. Available from: https://doi.org/10.1007/s10198-01901050-5

46. Simon RW, Lively K. Sex, anger and depression. Vol. 88, Social Forces. 2010.

47. Kose T. Gender, income and mental health: The Turkish case. PLoS One. 2020 Apr 1;15(4).

48. Kastello JC, Jacobsen KH, Gaffney KF, Kodadek MP, Sharps PW, Bullock LC. Predictors of Depression Symptoms Among Low-Income Women Exposed to Perinatal Intimate Partner Violence (IPV). Community Ment Health J. 2016;52(6):68390.

49. Ettman CK, Cohen GH, Abdalla SM, Galea $\mathrm{S}$. Do assets explain the relation between race/ethnicity and probable depression in U.S. adults? PLoS One. 2020 Oct 1;15(10 October).

50. Krause N. Assessing the relationships among stress, god-mediated control, and psychological distress/well-being: Does the level of education matter? J Soc Psychol. 2019;159(1):2-14.

51. Matsumura K, Hamazaki K, Tsuchida A, Kasamatsu H, Inadera H, Kamijima M, et al. Education level and risk of postpartum depression: Results from the Japan Environment and Children's Study (JECS). BMC Psychiatry [Internet]. 2019 [cited 2020 Sep 21];19(1). Available from: https://doi.org/10.1186/s12888-019-24013

52. Di Florio A, Putnam K, Altemus M, Apter G, Bergink V, Bilszta J, et al. The impact of 
education, country, race and ethnicity on the self-report of postpartum depression using the Edinburgh Postnatal Depression Scale. Psychol Med. 2017;47(5):787-99.

53. Lopez V, Sanchez K, Killian MO, Eghaneyan BH. Depression screening and education: An examination of mental health literacy and stigma in a sample of Hispanic women. BMC Public Health [Internet]. 2018 [cited 2020 Oct 17];18(1). Available from: https://doi.org/10.1186/s12889-018-55164

54. Amoah PA, Phillips DR, Gyasi RM, Koduah AO, Edusei J. Health literacy and self-perceived health status among street youth in Kumasi, Ghana. Cogent Med [Internet]. 2017 [cited 2021 Jan 4];4(1):1275091. Available from: http://dx.doi.org/10.1080/2331205X.2016 .1275091

55. Vreeker A, Boks MPM, Abramovic L, Verkooijen S, Van Bergen AH, Hillegers $\mathrm{MHJ}$, et al. High educational performance is a distinctive feature of bipolar disorder: A study on cognition in bipolar disorder, schizophrenia patients, relatives and controls. Psychol Med [Internet]. 2016 Mar 1 [cited 2021 Feb 5];46(4):807-18. Available from:

/pmc/articles/PMC5824688/?report=abst ract

56. Kim Y, Jang E. Low self-rated health as a risk factor for depression in south korea: A survey of young males and females. Vol. 9, Healthcare (Switzerland). 2021.

57. Ambresin G, Chondros P, Dowrick C, Herrman H, Gunn JM. Self-Rated Health and Long-Term Prognosis of Depression. Ann Fam Med [Internet]. 2014 Jan 1 [cited 2020 Oct 29];12(1):57-65. Available from: http://www.annfammed.org/cgi/doi/10. 1370/afm.1562

58. Jang Y, Yoon H, Li M, Park NS, Chiriboga $\mathrm{DA}, \mathrm{Wu}$ B, et al. Self-rated health as a mediator between physical health conditions and depressive symptoms in older Chinese and Korean Americans. Vol. 16, PLoS ONE. 2021.

59. Ko Y, Boo S. Self-perceived health versus actual cardiovascular disease risks. Japan J Nurs Sci [Internet]. 2016 Jan 1 [cited 2021 Jan 26];13(1):65-74. Available from: http://doi.wiley.com/10.1111/jjns.12087
60. Leão T, Perelman J. Depression symptoms as mediators of inequalities in selfreported health: The case of Southern European elderly. J Public Heal (United Kingdom) [Internet]. 2018 Dec 1 [cited 2021 Oct 20];40(4):756-63. Available from: https://academic.oup.com/jpubhealth/ar ticle/40/4/756/4779873

61. Viinikainen J, Bryson A, Böckerman P, Elovainio M, Pitkänen N, Pulkki-Råback L, et al. Does education protect against depression? Evidence from the Young Finns Study using Mendelian randomization. Prev Med (Baltim) [Internet]. 2018;115(March):134-9. Available from: https://doi.org/10.1016/j.ypmed.2018.08. 026

62. Fujiwara T, Kawachi I. Is education causally related to better health? A twin fixed-effect study in the USA. Int J Epidemiol [Internet]. 2009 Oct 1 [cited 2021 Oct 20];38(5):1310-22. Available from: https://academic.oup.com/ije/article/38 $/ 5 / 1310 / 664221$

63. Perna L, Zhang Y, Matias-Garcia PR, Ladwig KH, Wiechmann T, Wild B, et al. Subjective mental health, incidence of depressive symptoms in later life, and the role of epigenetics: results from two longitudinal cohort studies. Transl Psychiatry [Internet]. 2020 Dec 1 [cited 2021 Jan 26];10(1):1-8. Available from: https://doi.org/10.1038/s41398-02000997-x 